WellBeing International

WBI Studies Repository

$12-2010$

\title{
Salmon for Terrestrial Protected areas
}

\author{
Chris T. Darimont \\ University of California, Santa Cruz \\ Heather M. Bryan \\ University of Calgary \\ Stephanie M. Carlson \\ University of California, Berkeley \\ Morgan D. Hocking \\ Simon Fraser University \\ Misty MacDuffee \\ Raincoast Conservation Foundation
}

See next page for additional authors

Follow this and additional works at: https://www.wellbeingintlstudiesrepository.org/envncon

Part of the Animal Studies Commons, Natural Resources and Conservation Commons, and the Terrestrial and Aquatic Ecology Commons

\section{Recommended Citation}

Darimont, C. T., Bryan, H. M., Carlson, S. M., Hocking, M. D., MacDuffee, M., Paquet, P. C., ... \& Wilmers, C. C. (2010). Salmon for terrestrial protected areas. Conservation Letters, 3(6), 379-389.

This material is brought to you for free and open access by WellBeing International. It has been accepted for inclusion by an authorized administrator of the WBI Studies Repository. For more information, please contact wbisr-info@wellbeingintl.org.

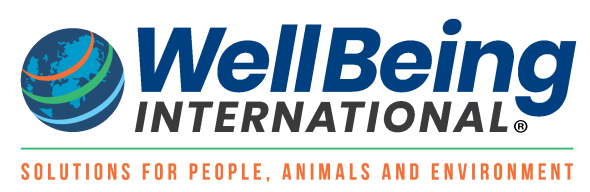




\section{Authors}

Chris T. Darimont, Heather M. Bryan, Stephanie M. Carlson, Morgan D. Hocking, Misty MacDuffee, Paul C. Paquet, Michael H. H. Price, Thomas E. Reimchen, John D. Reynolds, and Christopher C. Wilmers 


\title{
Salmon for terrestrial protected areas
}

\author{
Chris T. Darimont ${ }^{1,2}$, Heather M. Bryan ${ }^{2,3}$, Stephanie M. Carlson ${ }^{4}$, Morgan D. Hocking ${ }^{5}$, Misty MacDuffee ${ }^{2}$, \\ Paul C. Paquet ${ }^{2,6}$, Michael H.H. Price ${ }^{2,7}$, Thomas E. Reimchen ${ }^{7}$, John D. Reynolds ${ }^{5}$, \& Christopher C. Wilmers ${ }^{1}$ \\ ${ }^{1}$ Environmental Studies Department, University of California, Santa Cruz, CA 95064, USA \\ 2 Raincoast Conservation Foundation, Denny Island, BC, Canada VOT 1BO \\ ${ }^{3}$ Department of Ecosystem and Public Health, University of Calgary, AB, Canada T2N 4N1 \\ ${ }^{4}$ Department of Environmental Science, Policy and Management, University of California, Berkeley, CA 94720, USA \\ ${ }^{5}$ Department of Biological Sciences, Simon Fraser University, BC, Canada V5A 156 \\ ${ }^{6}$ Environmental Design, University of Calgary, Calgary, AB, Canada T2N 1N4 \\ ${ }^{7}$ Department of Biology, University of Victoria, Victoria, BC, Canada V8W 3N5
}

\section{Keywords}

Ecosystem-based fisheries management; freshwater; marine subsidies; protected areas; salmon; Oncorhynchus; terrestrial.

\section{Correspondence}

Chris T. Darimont, Environmental Studies Department, University of California, Santa Cruz, 405 Interdisciplinary Sciences Building, 1156 High Street, Santa Cruz, CA 95064, USA. Tel: (831) 459 2634; fax: (831) 4594015.

E-mail: darimont@ucsc.edu

\section{Received}

13 April 2010

Accepted

6 September 2010

\section{Editor}

Justin Brashares

doi: $10.1111 / j .1755-263 \times .2010 .00145 . x$

\begin{abstract}
Although managers safeguard protected areas for migratory species, little consideration has been given to how migratory species might benefit parks. Additionally, whereas land-sea connections are considered in management of protected areas, most effort has focused on reducing negative "downstream" processes. Here, we offer a proposal to promote positive "upstream" processes by safeguarding the seasonal pulse of marine nutrients imported into freshwater and riparian ecosystems by spawning migrations of Pacific salmon. Currently, high rates of fishing limit this important contribution to species and processes that terrestrial parks were designed to protect. Accordingly, we propose limiting exploitation in areas and periods through which salmon runs bound for terrestrial protected areas can migrate. Best suited for less commercially valuable but relatively abundant and widespread pink and chum salmon $(O$. gorbuscha and keta), our proposal thus considers ecosystem and societal needs for salmon. We conclude by outlining strategies to overcome socio-economic barriers to implementation.
\end{abstract}

\section{Introduction}

The primary goal of most protected areas is to provide clearly defined geographical refuges for conserving biodiversity. Such hard boundaries, however, cannot always capture the movement of mobile species or the diffuse nature of many natural processes. Planning for migratory species is especially difficult because their movements can be larger than the protected areas themselves. For example, large migratory fish often are not sufficiently protected by marine protected areas because of fishing pressure outside reserves (e.g., West et al. 2009). Helpful solutions have emerged in management of terrestrial protected areas. Efforts to protect migratory ungulates, for example, have focused on creating large core reserves coupled to adjacent buffer areas or other protected areas, even across national boundaries (Berger 2004; Thirgood et al. 2004). Whereas achievements like these have safeguarded terrestrial protected areas to benefit migratory species, our review-on which we expand belowsuggests that little consideration has been given to protecting migratory species to benefit terrestrial protected areas.

In addition to species, other materials also can flow into and out of protected areas, including energy, nutrients, and pollution, even across boundaries among different ecosystems (e.g., marine, freshwater, and terrestrial). What is increasingly appreciated is that protected areas are not closed ecological systems that operate without inputs from nearby systems (Stoms et al. 2005). Planning in 
coastal areas, for example, has identified important landsea connections to preserve the ecological structure and processes of marine protected areas. The focus of these approaches, however, has been on "downstream effects"; that is, how land use such as agriculture or logging can alter the function or value of the near shore environment (Stoms et al. 2005; Tallis et al. 2008; Halpern et al. 2009). Here, we present a case study that focuses on preserving important "upstream" processes. We offer a proposal of increased protection from exploitation for migratory Pacific salmon (Oncorhynchus spp.) because salmon destined for terrestrial protected areas make important contributions to these sites.

In developing our proposal, we considered the socioeconomic value of salmon, realizing that blanket reductions in salmon harvest are unlikely to be implemented. As we explain below we believe that a focus on pink and chum salmon (O.gorbuscha and keta), however, provides opportunity to implement our ideas without severe economic consequences. Nonetheless, given the socioeconomic and cultural values of salmon, managers and decision makers might perceive our proposal as radical. We note, however, that the principles of fisheries management and applied conservation ecology often depart conceptually because of differing goals. Accordingly, we conclude by highlighting how our proposal ultimately might yield economic and management benefits as well as strategies by which barriers to implementation might be overcome.

\section{Pacific salmon as migratory, cross-boundary species that contribute to terrestrial protected areas}

Pacific salmon migrate over large distances but differ from other migrants like ungulates, birds and butterflies in fundamental ways. First, they cross boundaries among freshwater, oceanic, and terrestrial systems. They are born in freshwaters and then migrate over thousands of kilometers through the ocean for 18 months to 6 years, depending on the species. As reproductive adults, they return to natal streams to spawn, some traveling upstream 1,000 $\mathrm{km}$ or more. Pacific salmon also have a distinct life history in which individuals in most populations senesce after this migration. Their bodies are often transported further "upstream" into riparian areas by terrestrial predators and scavengers, like bears (Ursus spp.), where their remains and nutrients become available to a diversity of other animal consumers as well as vegetation (e.g., Reimchen 1994, 2000; Willson \& Halupka 1995; Ben-David et al. 1998; Cederholm et al. 1999; Gende et al. 2002; Naiman et al. 2002; Schindler et al. 2003; Quinn et al. 2009). These salmon migrants therefore provide important contribu- tions to the freshwater and riparian ecosystems where they breed, which are often nutrient limited.

The dominant model that describes the contribution of salmon to these areas identifies them as resource subsidies, originating in one ecosystem and benefiting another (Polis et al. 1997). Because salmon obtain most of their body mass at sea, individuals that survive the oceanic stage import a net positive quantity of marinederived nutrients into spawning areas. This "fertilizer effect" can influence bottom-up ecosystem processes such as primary production, decomposition, and mineral cycling (e.g., Zhang et al. 2003; Mitchell \& Lamberti 2005; Hocking $\&$ Reimchen 2009) and top-down processes involving competition and predation (e.g., Ben-David et al. 2004; Gende \& Quinn 2004; Darimont et al. 2008). The breakdown of salmon carcasses in terrestrial habitats also creates areas of high nutrient release (Holtgrieve et al. 2009), which ultimately can affect communities of riparian plants, terrestrial and freshwater invertebrates, resident fish, and songbirds (Bilby et al. 1998; Mathewson et al. 2003; Wilkinson et al. 2005; Christie \& Reimchen 2008; Hocking \& Reimchen 2009; Hocking et al. 2009).

Another principal concept describes salmon as ecosystem engineers. Salmon modify creek substrates while spawning and suspend nutrient-rich sediments and salmon eggs in the water column, resulting in substantive nutrient export to estuaries and downstream lakes (Moore et al. 2007, 2008). This process can alter the production of biofilm, rates of detrital processing, and the seasonal abundance of freshwater consumers. Collectively, these observations suggest that spawning activity can represent a key component of coupled marine-freshwater nutrient cycling (Mitchell \& Lamberti 2005; Lessard \& Merritt 2006).

In addition to a key role played by salmon in ecological interactions, coevolutionary association with other species are also evident. For example, there is evidence that aquatic insects may time their emergence from streams as adults such that they avoid disturbance caused by spawning salmon (Moore \& Schindler 2010). It has also been shown that the timing of lactation in mink (Mustela vison) - which is decoupled from that predicted by latitude-occurs during salmon spawning periods (Ben-David 1997). Salmon availability can also increase niche diversity within consumer populations (Hocking et al. 2007; Darimont et al. 2009a), which is important because foraging behavior is a central and influential trait on which natural selection can act. Salmon have also been linked to the maintenance of a rare polymorphic trait; recent evidence indicated that the unusual white phase of the black bear (U. americanus) in coastal British Columbia, Canada might be a salmon specialist (Klinka \& Reimchen 2009). 
Figure 1 Example of how migratory salmon biomass is exploited by different users in the near shore and terrestrial environments. Catch by commercial, recreational, and subsistence fishers is set conservatively at 50\%, though in some systems it may be as high as $90 \%$. The remaining salmon only then become available to a suite of consumers and scavengers in estuarine, freshwater, and forested areas of spawning environments. Postfishing proportions were adapted from empirical estimates that focused on terrestrial vertebrate and diperan predators and scavengers in Reimchen (1994) from Bag Harbour, Haida Gwaii, British Columbia.

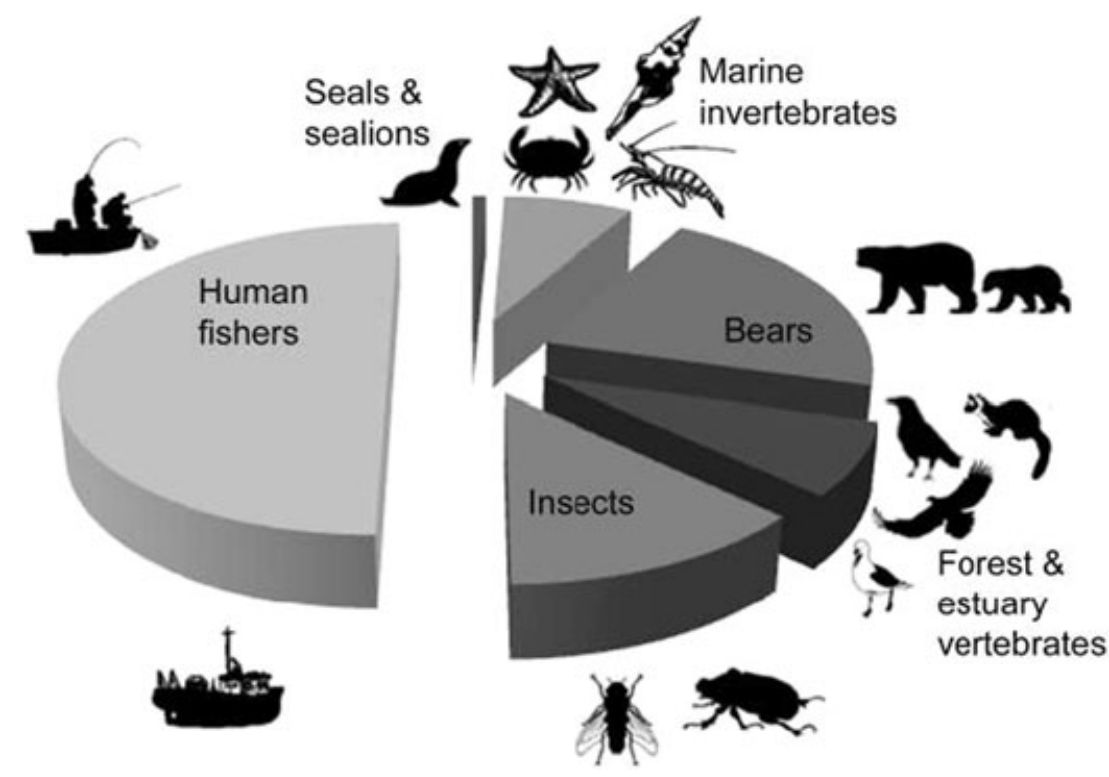

\section{Exploited salmon connections}

Among myriad human influences that can influence wild salmon numbers (and thus their contributions to ecosystems; e.g., climate change, habitat loss, pollution, hatcheries), exploitation in near shore waters-often just a few kilometers from spawning areas-directly affects spawner numbers (Figure 1). Commercial, recreational and subsistence fisheries, the former usually subsidized by governments, often catch $50 \%$, and as high as $90 \%$, of returning adult salmon from near shore waters (Quinn 2005). Although cycles of salmon productivity regulated by at-sea conditions are common (Mueter et al. 2002), at any level of productivity fisheries harvests reduce the amount of salmon that return to spawning areas. Importantly, exploitation rates do not vary as a function of whether runs return to terrestrial protected areas.

Interception of much of this yearly mass migration limits the formerly large-scale uploading of marine nutrients and energy into near shore, freshwater, and terrestrial habitats. For example, Reimchen (1995) calculated that commercial fisheries in waters adjacent to Haida Gwaii (British Columbia, Canada) on average take twice as much salmon biomass as pinnipeds and marine birds combined. More detailed estimates of the drawdown of salmon-derived nutrients entering spawning areas are rare in the peer-reviewed literature. Schindler et al. (2005) estimated that commercial fisheries have intercepted about two-thirds of marine-derived nutrients since about 1900 that would have otherwise been received by a lake in Alaska, leading to a strong drop in algal productivity (but not salmon production).
Below we explore the implications of this exploitation for the ecosystems and species that salmon nourish and for which some terrestrial protected areas were in fact created. This conservation paradox-and the fact that managers of terrestrial protected areas currently have little influence over exploitation levels on salmon runs bound for terrestrial protected areas-has motivated us to seek a remedy. We provide support for our proposal by assessing how ecosystems might respond by restoring these mass migrations, with a focus on terrestrial protected areas of British Columbia.

\section{Salmon and terrestrial protected areas in British Columbia, Canada}

There are serious concerns about the viability of many wild salmon populations in British Columbia. Assessments during the 1990s indicated that the abundance of all five species had been reduced by $13-50 \%$ compared with historical estimates (Northcote \& Atagi 1997; see also Slaney et al. 1996; Gresh et al. 2000). More recently, Price et al. (2008) noted that only $4 \%$ of monitored streams in British Columbia were meeting management targets for "escapements" (i.e., numbers of salmon reaching spawning areas) set by Fisheries and Oceans Canada.

Concurrent with these declines in salmon, the area covered by terrestrial protected areas (provincial parks and ecological reserves as well as federal parks) has recently increased in British Columbia. The provincial government, which manages most of British Columbia's 


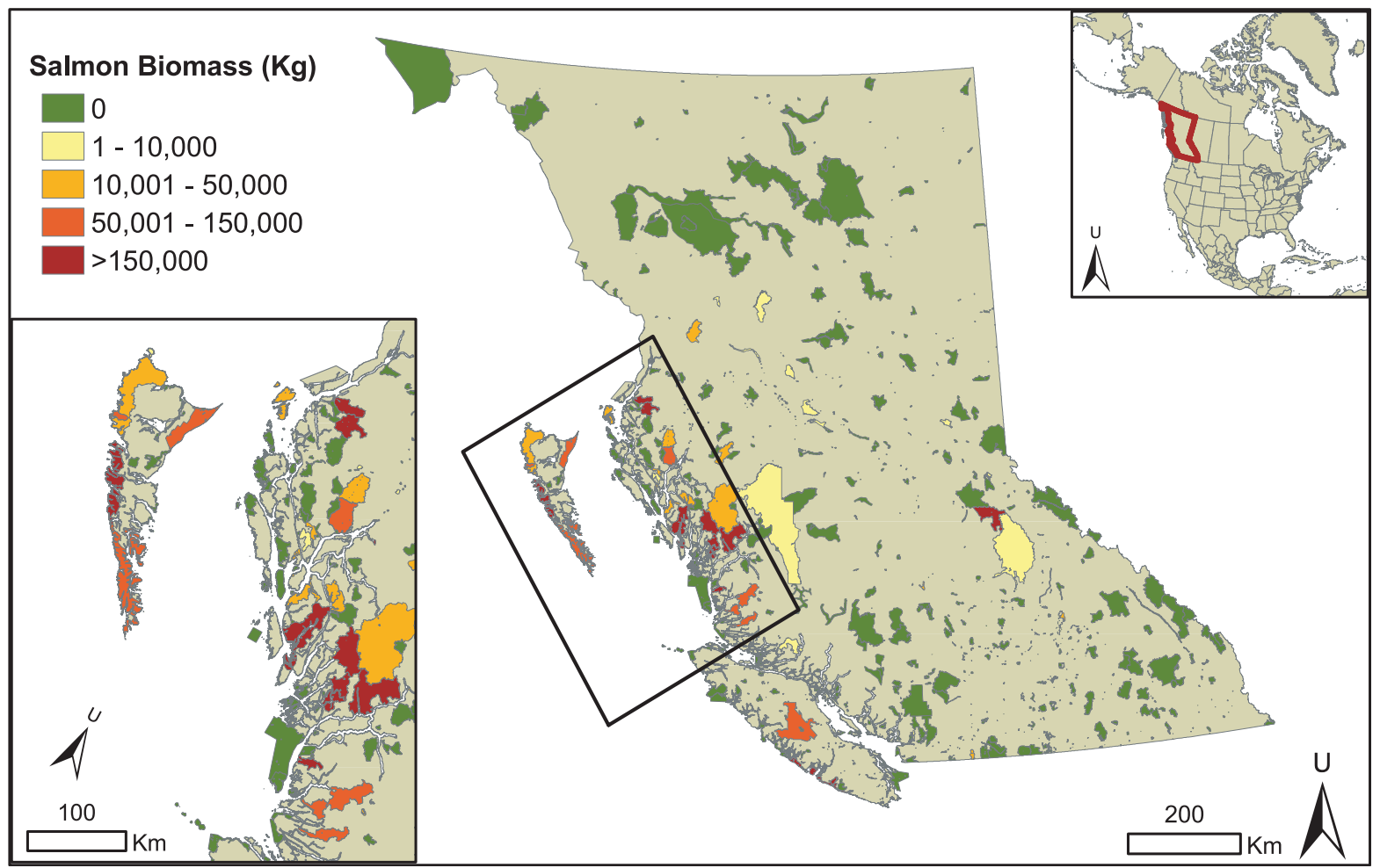

Figure 2 Average (1999-2008) yearly spawning salmon biomass (kilograms) in terrestrial protected areas of British Columbia (provincial and national parks as well as ecological reserves). Biomass was calculated at spatial points where enumeration occurred (Fisheries and Oceans Canada, unpublished data). Consequently, some runs that might spawn in part within protected areas were assigned to unprotected areas, and vice versa. Coastal protected areas (inset) host $70 \%$ of the spawning biomass within British Columbia's parks. protected areas, recently announced a large increase in terrestrial protected areas. Approximately 1.3 million ha were added in 2007 across 85 new coastal conservancies on British Columbia's coast. These areas host high salmon densities and represent $70 \%$ of all salmon biomass returning to British Columbia's parks (Figure 2). Province-wide about $20 \%$ of salmon runs, representing roughly $30 \%$ of the average spawning biomass over the last decade, return to terrestrial protected areas (Table 1).

Table 1 Proportions of salmon spawning waterways (and their estimated collective yearly biomass) in British Columbia that occur within protected areas (provincial and national parks as well as ecological reserves). Runs (geo-referenced to enumeration points) were included if they were monitored at least five times during the decade; biomass proportions are based on 10-year (1999-2008) escapement averages (Fisheries and Oceans Canada, unpublished data). Biomass calculations were estimated using average mass of each species and sex, assuming a 1:1 sex ratio (Groot \& Margolis 1991). Mapping and calculations were performed in ArcGIS 9.3 (ESRI, Inc.).

\begin{tabular}{lcc}
\hline Species & Proportion of runs in TPAs (\%) & Proportion of biomass (kilotonnes) in TPAs (\%) \\
\hline Chinook (O. tshawytscha, Walbaum) & $33 / 193(17.1)$ & $1.6 / 8.3(19.3)$ \\
Chum (O. keta, Walbaum) & $97 / 421(23.0)$ & $4.4 / 12.0(36.4)$ \\
Coho (O. kisutch, Walbaum) & $64 / 388(16.5)$ & $0.5 / 1.9(24.8)$ \\
Pink (O. gorbuscha, Walbaum); even year ${ }^{\text {a }}$ & $82 / 271(30.3)$ & $3.8 / 10.3(37.4)$ \\
Pink; odd year & $82 / 271(30.3)$ & $6.6 / 15.9(41.3)$ \\
Sockeye (O. nerka, Walbaum) & $68 / 301(22.6)$ & $1.3 / 13.8(9.5)$ \\
All species & $189 / 897(21.1)$ & $18.2 / 62.2(29.2)$
\end{tabular}

${ }^{a}$ Pink salmon have an invariable 2-year life cycle; even and odd year populations do not interbreed. Consequently, data are commonly presented separately. 


\section{Our proposal}

We propose that some salmon populations ("runs"), or considerable portions thereof, that are bound for British Columbia terrestrial protected areas be granted protection from exploitation. Our idea can be traced to an early call for salmon ecosystem management. Reimchen (1995) argued that the commercial extraction of salmon would directly limit the carrying capacity of the estuarine and terrestrial environments of a proposed terrestrial protected area (Gwaii Haanas National Park Reserve, British Columbia); a proposal, ultimately unsuccessful, was offered to park managers that extraction be scaled back gradually to pre-European-contact exploitation to restore the ecosystem.

In presenting our case, we differentiate it from other calls for salmon ecosystem conservation. First, our proposal departs from management aimed at enhancing fisheries values. For example, there have been calls for fixed catches, allowing escapement to vary (Hilborn 2006). It also differs from salmon "stronghold" proposals, which focus on terrestrial and riverine protection for salmon (e.g., Lichatowich et al. 2000). Second, as we detail further, our proposal prioritizes safeguarding specific species and populations, while acknowledging that fishing will occur on others. Similar plans to restore salmon nutrients can be extended subsequently to other populations and species, should managers and society consider the approach valuable. Third, our proposal would involve reciprocity. Currently, managers of terrestrial protected areas provide critical habitat protection to salmon, with benefits to salmon managers and fishers. In return, however, fisheries managers permit high exploitation on returning adults, often just kilometers from terrestrial protected areas. Our proposal suggests that fisheries managers return the favor, though not as a transition from one asymmetric relationship to another. Dense spawning runs envisaged by this proposal could promote dispersal and rescue effects to spawning areas of nearby (fished) runs. Although an untested hypothesis, such a "spillover effect" (Roberts et al. 2001) from a network of terrestrial protected area runs might potentially result in ecological and economic resilience of the nearby fisheries (Healey 2009; see also Schindler et al. 2010).

Technical solutions that can overcome barriers to this proposal are possible. For example, terminal commercial fisheries (in which fish of known populations are exploited at river mouths and in rivers) and area-based recreational fisheries could support continued fishing of runs bound for areas outside of terrestrial protected areas while protecting "corridor" areas (and periods) through which terrestrial protected area runs can migrate. Dis- criminating among runs harvested beyond river mouths can be supported by emerging knowledge of near shore adult migration routes and schedules. This information can be complemented by another imperfect but nonetheless potentially valuable management resource for stock differentiation: rapid genetic analyses on field-sampled individuals in test fisheries prior to fishing (e.g., Beacham et al. 2004).

Political barriers to any proposed changes to the primarily mixed-stock exploitation model, however, are significant. At the broadest scale, for example, integrating additional complexity into the already complicated and often disputed U.S.-Canada Pacific Salmon Treaty (Noakes et al. 2005) would likely face considerable opposition. At a regional scale, commercial license holders would object strongly to any changes that restrict harvests or modify where they occur. Moreover, in coastal British Columbia, the strength of First Nations' cultural identity with salmon is matched only by their increasing legal entitlement to this resource. Furthermore, many groups co-manage several of the new terrestrial protected areas and have developed their own land and resource management plans. Accordingly, any proposal will require meaningful dialogue about trade-offs among cultural, socio-economic, and conservation values.

We fine-tune our proposal here by highlighting how these technical and political challenges vary by species as a function of their different life histories and economic values (for summary of these differences, see Quinn 2005). From a commercial perspective, our plan would not be reasonable for Chinook and coho salmon (O. tshawytscha and kisutch), which spend much of their lives along the near shore waters of western North America and thus are continuously vulnerable to fishing by multiple jurisdictions. In contrast, pink, chum, and sockeye salmon (O. gorbuscha, keta, and nerka) spend most of their lives offshore. Although significant exceptions exist (e.g. Fraser River sockeye are captured several hundred kilometers from the mouth of the Fraser in both Canadian and U.S. waters), these species are often fished in a more terminal manner, which more readily permits discrimination among stocks. Additionally, pink, chum, and sockeye contribute most of the marine subsidy and to a large diversity of streams in western North America (Quinn 2005). Finally, chum and pink would be the most appropriate early targets for changes to management because they are the least commercially valuable salmon. For example, ex-vessel prices in Alaska for these two species in 2002 were $\$ 0.06$ and $\$ 0.16$ /pound, compared to $\$ 0.37, \$ 0.55$, and $\$ 1.23$ for coho, sockeye, and Chinook, respectively; the same ranking and similar proportional differences among species also occurred in the late 1980s and 1990s (Eagle et al. 2003). 


\section{Link to multiple policy initiatives}

Our proposal is consistent with several emerging policies. At the broadest scale, our proposal to allocate more salmon to ecosystems is consistent with a global movement towards ecosystem-based fishery management. In theory, this management paradigm reverses the order of management priorities to start with the ecosystem rather than maximizing catches of target species (Pikitch et al. 2000). Minimally, it can include nonfishing values as criteria in evaluating trade-offs among harvesting options (Kellner et al. in press). Moreover, in Canada, a novel landmark policy of the federal government (Wild Salmon Policy, Fisheries and Oceans Canada 2005) has explicitly recognized that nonhuman users of salmon-including those in the terrestrial and freshwater domains-ought to be considered in fisheries management. A specific plan by which such allocation could occur, however, has not yet been proposed.

Another direct policy link relates to terrestrial protected area planning now occurring in coastal British Columbia. At a broad level, planning by British Columbia parks is guided by a conservation principle "to protect and manage lands and natural and cultural values within, and adjacent to, the province's parks" and a strategy to "work with other areas of government" (British Columbia Ministry of Environment 2008). These guiding values could be applied to exerting influence on federally managed fishing levels imposed on runs bound for terrestrial protected areas. Indeed, salmon declines have been identified as a threat to parks. The management plan for the massive Kitlope Conservancy, for example, highlighted the severe recent declines in salmon. Stocks of chum, pink, and coho (O. gorbuscha, keta, and kisutch) during the park's first decade (1991-2001) were less than $10 \%$ of mean levels observed during the previous four decades (British Columbia Ministry of Environment 2007).

\section{Implications of restoring salmon contributions to terrestrial protected areas}

Trading off fisheries catches for the restoration of ecological services provided by spawning salmon might positively affect terrestrial ecosystems and the species and processes for which many terrestrial protected areas were created. For example, salmon abundance has been linked positively to the productivity of its consumers. In grizzly bears (Ursus arctos horribilis), individuals and populations with greater access to salmon had greater litter and body sizes, as well as population density and productiv- ity (Hilderbrand et al. 1999; Mowat \& Heard 2006). On smaller scales, forests adjacent to rivers (or reaches) with salmon had higher songbird density than those without (Gende \& Willson 2001; Christie \& Reimchen 2008). Salmon subsidies can positively affect resident fishes too (e.g., Scheuerell et al. 2007). In Alaska, Denton et al. (2009) found that Dolly Varden trout (Salvelinus malma) foraged heavily on sockeye salmon (O. nerka) eggs and juveniles as well as on blowfly maggots (family Calliphoridae) that themselves had foraged on adult salmon carcasses; growth rates increased significantly once eggs and maggots were seasonally available.

Particularly compelling support for an "abundance matters" hypothesis occurs in studies that have linked salmon productivity with ecological processes through space and/or time. For example, Schindler et al. (2005) showed a strong positive relationship between estimated salmon escapement and algal pigments (a proxy for primary production) in a sockeye lake in Alaska over a 300-year period. On a smaller spatial and temporal scale, analyses of tree ring growth suggest that riparian plant productivity was positively associated with salmon abundance among and within watersheds through time (Helfield \& Naiman 2001; Reimchen et al. 2003). Emerging across-watershed studies demonstrate how salmon density and habitat interact to affect terrestrial ecosystem processes (e.g., Selbie et al. 2009; Hocking \& Reimchen 2009). Moreover, a recent meta-analysis of 37 publications on 79 salmon-bearing waterways identified variable, yet overall positive, associations between carcass density and the abundance of several response variables: dissolved nutrients, sediment biofilm, and densities of macroinvertebrates and resident fish (Janetski et al. 2009). Whereas many of the responses will be positive, there might also be negative population consequences for competing species. Unambiguously, however, consumption of any amount of salmon by in situ consumers (e.g., bears, birds, and so on) results in no net loss of trophic biomass to a recipient community within a spawning watershed in a given year, whereas a similar sized removal by fisheries yields a distinct loss of that biomass.

Restoring salmon to terrestrial protected areas also might restore natural evolutionary processes now potentially modified by fishing. For example, salmon runs free from fisheries-induced selection might restore size and run timing distributions within populations previously altered by selective mortality imposed by fisheries (Quinn et al. 2007; Hard et al. 2008; Darimont et al. 2009b). In an era of climate change, increased variation in run timing within and among salmon populations might increase resilience to harmful water temperatures or other factors that might alter spawning environments in the future. 


\section{Policy-relevant recommendations for implementation}

(1) Engage participants in, and champions of, salmon ecosystem restoration. Any proposal to restrict human activity, particularly one counter to dominant models of industry and resource management, risks failure or unintended negative consequences. For example, should our proposal or elements thereof be implemented, future calls for increased terrestrial protected areas might face resistance from new opponents (i.e., fishing interests). Consequently, our plan needs champions. Those charged with protecting the freshwater life stages of salmon, and whose terrestrial protected areas can reap the benefits of their restoration, are ideal. Likewise, scientists and managers can speak to the plan's benefits. Unexploited "baseline" runs can provide: (i) measures against which the effects of region-wide environmental change can be gauged, and (ii) a "best management" practice against which other treatments (i.e., exploitation levels) can be compared. Moreover, monitoring salmon populations and the ecosystems they subsidize pre- and post-implementation can permit testing of the "spillover" and "abundance matters" hypotheses described earlier. In short, such an adaptive management experiment on a large spatial scale could permit a better understanding of the value of salmon to terrestrial watersheds than historical scientific approaches, which have necessarily occurred across studies scattered over space and time.

(2) Reduce exploitation on specific runs of salmon bound for terrestrial protected areas. As discussed previously, our proposal might be most easily implemented on specific species-namely pink and chum salmon-for several reasons, including that they spawn at high densities and so contribute substantial marine subsidies to upstream areas, spend most of their lives offshore, are fished in a terminal manner, and because they are the least commercially valuable of the Pacific salmon. For these reasons, we believe that a reduction in exploitation on pink and chum bound for terrestrial protected areas could maximize ecological benefits of salmon while minimizing the economic impacts of harvest reduction, and thus represents a compromise between ecological and societal demands for salmon resources.

(3) Reduce exploitation on terrestrial protected areas-bound runs on a graduated schedule. Our proposal requires cooperation from fishers. Allowing time for these stakeholders to adjust to reduced fishing levels gradually could mitigate potential conflict by distinguishing our proposal from an immediately imposed and drastic reduction in exploitation levels. Likewise, early implementation among select terrestrial protected areas, starting with pilot areas that can be monitored and assessed, would likewise ease the transition. Finally, the best targets for early implementation would be runs that are already closed for fishing because of low returns.

(4) Provide alternative economic models. A realistic plan to support such a transition requires alternative models of generating economic wealth from salmon. This includes a conversion to terminal fisheries on nonterrestrial protected areas runs, which underlies our proposal. Shifting commercial opportunities from industrial boats involved in mixed-stock fisheries to local in-river fishers is central to resilient economic models of fishing (Healey 2009). A transition like this is currently underway in north coastal British Columbia, where an in-river, terminal fishery on the Skeena River has generated increased employment (via local processing and marketing of fish) and better prices (Taylor \& Dickie 2009). We speculate, too, that greater salmon returns to terrestrial protected areas might support increased economic opportunities in wildlife viewing (e.g., bears, Bald Eagles [Haliaeetus leucocephalus], and killer whales [Orcinus orca]) as well as other salmon-reliant ecotourism activities (e.g., Clayton \& Mendelsohn 1993). Our proposal notwithstanding, these are important opportunities, especially when future revenues from fishing are uncertain; in British Columbia, conservation concerns have already prompted widespread mixedstock commercial fishing closures and will likely do so into the future (Fisheries and Oceans Canada 2010). Finally, for healthier runs, allowing increased escapements might not cause a proportionate decline in revenues; Hilborn (2006) noted that high catch years for sockeye salmon in Alaska lead to poorer quality fish that fetched reduced prices.

(5) Evaluate the "over-escapement" paradigm. One of the primary models that drives fisheries policy is Ricker (1954), which predicts a reduction in offspring produced at high spawning densities. Its prominence has led to the general belief that if "too many" salmon spawn, fewer fish will return in the next generation. A comprehensive review, however, found that although the process occurs occasionally it does not drive population collapses (Walters et al. 2004). The argument is likely moot, however, for many salmon populations in British Columbia, which host spawning levels below densities at which densitydependence would occur (e.g., Price et al. 2008). 
Nonetheless, depending on the nature of the densitydependent relationship, we acknowledge that protecting $100 \%$ of a run might not be the right goal. A modest exploitation rate on runs bound for terrestrial protected areas might simultaneously provide economic benefits and increase run productivity in subsequent generations (to be shared among humans and the terrestrial ecosystem). Minimally, a carefully monitored change to exploitation levels can permit further examination of the "over-escapement" paradigm.

(6) Foster increased integration between fisheries and parks managers. A fragmented governance structure for salmon often undermines conservation management (Kolmes \& Butkus 2006). We recommend increased integration-at minimum through the establishment of liaison positions and joint meetings-between federal salmon managers and protected area managers from federal, provincial, and aboriginal governments (who also manage freshwater salmon habitat). This would be consistent with repeated calls for integrated planning that led a British Columbia government advisory body to call for a "Water and Land Agency"; this organization would break down silos to make all decisions concerning land and water use, including in marine environments, based on ecosystem-wide considerations (British Columbia Salmon Forum 2009).

\section{Conclusion}

We began this collaboration asking, "Are terrestrial protected areas that host highly exploited salmon runs truly protected?" Evidence we have provided suggests not. In an era when protected areas are becoming increasingly "humanized" by accommodating resource extraction that undermines the notion of protection (Locke $\delta$ Dearden 2005), we have presented a remedy that involves "dehumanizing" the footprint on migratory salmon bound for terrestrial protected areas. However, given the socioeconomic and cultural values of salmon, coupled with a legacy of highly exploitative management, the ecocentric prescription we have offered will undoubtedly be viewed by some as radical. Yet, what might be defiant from a management perspective would be considered an important restoration activity —or at minimum an opportunity for natural experimentation-by many ecologists. Although some might deem our idea politically unachievable, our aim is to inform and inspire decision-makers with a plan that not only favors biodiversity but also one that ultimately might yield economic and management benefits. Our goal is to inoculate the literature with a provocative idea to stimulate discussion.
Recognizing that important linkages exist between protected areas and nearby lands or waters (Stoms et al. 2005), promoting positive upstream processes like salmon migrations should be granted the same consideration as minimizing negative downstream processes such as habitat modification. This might be important because migrations in general are becoming increasingly endangered phenomena (Berger 2004). Salmon are not alone among migrants in providing important biological services to areas they visit; ungulates stimulate primary productivity; butterflies pollinate; birds distribute seeds and so on. Accordingly, if these central ecological processes are valued in protected area management, increased consideration should be granted to protecting migratory species bound for their borders.

\section{Acknowledgments}

CTD and MDH were supported by National Science and Engineering Research Council (NSERC) postdoctoral fellowships, and HMB and MHHP by NSERC postgraduate scholarships. CCW was supported by an NSF grant no. 0963022. We thank Patagonia and the Wilburforce Foundation for funding, the Spatial Pattern Analysis and Research laboratory at the University of Victoria for assistance with GIS data, Fisheries and Oceans Canada for sharing salmon escapement data, and P. Dearden and two anonymous reviewers for providing thoughtful feedback on earlier versions of this manuscript.

\section{References}

Beacham, T.D., Lapointe M., Candy J.R., Miller K.M., Withler R.E. (2004) DNA in action: rapid application of DNA variation to sockeye salmon fisheries management. Conserv Genet 5, 411-416.

Ben-David, M. (1997) Timing of reproduction in wild mink: the influence of spawning Pacific salmon. Can J Zool 75, 376-382.

Ben-David, M., Hanley T.A., Schell D.M. (1998) Fertilization of terrestrial vegetation by spawning Pacific salmon: the role of flooding and predator activity. Oikos 83, 47-55.

Ben-David, M., Titus K., Beier L.R. (2004) Consumption of salmon by Alaskan brown bears: a trade-off between nutritional requirements and the risk of infanticide? Oecologia 138, 465-474.

Berger, J.S. (2004) The longest mile: how to sustain long distance migration in mammals. Conserv Biol 18, 320-332.

Bilby, R.E., Fransen B.R., Bisson P.A., Walter J.K. (1998) Response of juvenile coho salmon (Oncorhynchus kisutch) and steelhead (Oncorhynchus mykiss) to the addition of salmon carcasses to two streams in southwestern Washington, U.S.A. Can J Fish Aquat Sci 55, 1909-1918. 
British Columbia Ministry of Environment. (2007) Draft Huchsduwachsdu Nuyem Jees/Kitlope Heritage Conservancy Management Plan, Victoria, p. 90.

British Columbia Ministry of Environment. (2008) British Columbia Parks Program Plan 2007-2012, Victoria, p. 31.

British Columbia Salmon Forum. (2009) Final Report and Recommendations to the Government of British Columbia, Victoria, p. 96.

Cederholm, C.J., Kundze M.D., Murota T., Sibatani A. (1999) Pacific salmon carcasses: essential contributions of nutrients and energy for freshwater and terrestrial ecosystems. Fisheries 24, 6-15.

Christie, K.S., Reimchen T.E. (2008) Presence of salmon increases passerine density on Pacific North-west streams Auk 125, 51-59.

Clayton, C., Mendelsohn R. (1993) The value of watchable wildlife: a case study of McNeil river. J Environ Manage 39, 101-106.

Darimont, C.T., Paquet P.C., Reimchen T.E. (2008) Spawning salmon disrupt trophic coupling between wolves and ungulate prey in coastal British Columbia. BMC Ecol 8, 14.

Darimont, C.T., Paquet P.C., Reimchen T.E. (2009a) Landscape heterogeneity and marine subsidy generate extensive intrapopulation niche diversity in a large terrestrial vertebrate. J Anim Ecol 78, 126-133.

Darimont, C.T., Carlson S.M., Kinnison M.T., Paquet P.C., Reimchen T.E., Wilmers C.C. (2009b) Human predators outpace other agents of trait change. Proc Nat Acad Sci USA 106, 952-954.

Denton, K.P., Rich Jr. H.B., Quinn T.P. (2009) Diet, movement, and growth of Dolly Varden in response to sockeye salmon subsidies. Trans Am Fish Soc 138, 1207-1219.

Eagle, J., Naylor R., Smith W. (2003) Why farm salmon outcompete fishery salmon. Mar Policy 28, 259-270.

Fisheries and Oceans Canada. (2005) Canada's policy for conservation of wild Pacific salmon. Cat. No. Fs23-476/2005E. Vancouver, p. 57.

Fisheries and Oceans Canada. (2010) Pacific Region Draft \#1. Integrated Fisheries Management Plan-Salmon Northern British Columbia June 1, 2010-May 31, 2011. Vancouver, p. 100.

Gende, S.M., Edwards R.T., Willson M.F., Wipfli M.S. (2002) Pacific salmon in freshwater and terrestrial ecosystems. BioScience 52, 917-928.

Gende S.M., Quinn T.P. (2004) The relative importance of prey density and social dominance in determining energy intake by bears feeding on Pacific salmon. Can J Zool 82, 75-85.

Gende S.M., Willson M.F. (2001) Passerine densities in riparian forests of southeast Alaska: potential effects of anadromous spawning salmon. Condor 103, 624-629.

Gresh, T., Lichatowich J., Schoonmaker J. (2000) An estimation of historic and current levels of salmon production in the Northeast Pacific Ecosystem: evidence of a nutrient deficit in the freshwater systems of the Pacific Northwest. Fisheries 25, 15-21.

Groot, C., Margolis L. (1991) Pacific salmon life histories. University of British Columbia Press, Vancouver.

Halpern, B.S., Ebert C.M., Kappel C.V. et al. (2009) Global priority areas for incorporating land-sea connections in marine conservation. Conserv Lett 2, 189-196.

Hard, J.J., Gross M.R., Heino M. et al. (2008) Evolutionary consequences of fishing and their implications for salmon. Evol Appl 1, 388-408.

Healey, M.C. (2009) Resilient salmon, resilient fisheries for British Columbia, Canada. Ecol Soc 14, 2.

Helfield, J.M., Naiman R.J. (2001) Effects of salmon-derived nitrogen on riparian forest growth and implications for stream productivity. Ecology 82, 2403-2409.

Hilborn, R. (2006) Fisheries success and failure: the case of the Bristol Bay salmon fishery. Bull Mar Sci 78, 487-498.

Hilderbrand, G.V., Schwartz C.C., Robbins C.T. et al.(1999) The importance of meat, particularly salmon, to body size, population productivity, and conservation of North American brown bears. Can J Zool 77, 132-138.

Hocking, M.D., Darimont C.T., Christie K.S., Reimchen T.E. (2007) Niche variation in burying beetles (Nicrophorus spp.) associated with Pacific salmon carcasses. Can J Zool 85, 437-442.

Hocking, M.D., Reimchen T.E. (2009) Salmon species, density and watershed size predict magnitude of marine enrichment in riparian food webs. Oikos 118, 1307-1318.

Hocking, M.D., Ring R.A., Reimchen T.E. (2009) The ecology of terrestrial invertebrates on Pacific salmon carcasses. Ecol Res 24, 1091-1100.

Holtgrieve, G.W., Schindler D.E., Jewett P.K. (2009) Large predators and biogeochemical hotspots: brown bear (Ursus arctos) predation on salmon alters nitrogen cycling in riparian soils. Ecol Res 24, 1125-1135.

Janetski, D.J., Chaloner D.T., Tiegs S.D., Lamberti G.A. (2009) Pacific salmon effects on stream ecosystems: a quantitative synthesis. Oecologia 159, 583-595.

Kellner, J.B., Sanchirico J.N., Hastings A., Mumby P.J. (in press) Optimizing for multiple species and multiple values: tradeoffs inherent in ecosystem-based fisheries management. Conserv Lett doi: 10.1111/j.1755-263X.2010.00132.x

Klinka, D.R., Reimchen T.E. (2009) Adaptive coat colour polymorphism in the Kermode bear of coastal British Columbia. Biol J Linn Soc 98, 479-488.

Kolmes, S., Butkus R. (2006) Got wild salmon? A scientific and ethical analysis of salmon recovery in the Pacific Northwest and California. Pages 333-362 in R. Lackey, D. Lach, S. Duncan, editors. Salmon 2100: the future of wild Pacific salmon. American Fisheries Society, Maryland.

Lichatowich, J.A., Rahr G.A., Whidden S.M., Steward C.R. (2000) Sanctuaries for Pacific Salmon. Pages 675-686 in E. Knudsen, C.R. Donald Steward, D. MacDonald, J.E. 
Williams, D.W. Reiser, editors. Sustainable fisheries management: Pacific salmon. CRC Press, Boca Raton.

Lessard, J.L., Merritt R.W. (2006) Influence of marine-derived nutrients from spawning salmon on freshwater insect communities in southeast Alaskan streams. Oikos 113, 334-343.

Locke, H., Dearden P. (2005) Rethinking protected area categories and the "new paradigm". Environ Conserv 32 , $1-10$.

Mathewson, D., Hocking M.H., Reimchen T.E. (2003) Nitrogen uptake in riparian plant communities across a sharp ecological boundary of salmon density. BMC Ecol 2003, 4.

Moore, J.W., Schindler D.E., Carter JL., Fox J., Griffiths J., Holtgrieve G.W. (2007) Biotic control of stream fluxes: spawning salmon drive nutrient and matter export. Ecology 88, 1278-1291.

Moore, J.W., Schindler D.E., Ruff C.P. (2008) Habitat saturation drives thresholds in stream subsidies. Ecology $\mathbf{8 9}$, 306-312.

Moore, J.W., Schindler D.E. (2010) Spawning salmon and the phenology of emergence in stream insects. Proceedings of the Royal Society B 277, 1695-1703.

Mowat, G., Heard D.C. (2006) Major components of grizzly bear diet across North America. Can J Zool 84, 473-489.

Mitchell, N.L., Lamberti G.A. (2005) Responses in dissolved nutrients and epilithon abundance to spawning salmon in southeast Alaska streams. Limnol Oceanogr 50, 217-227.

Mueter, F.J., Peterman R.M., Pyper B.J. (2002) Opposite effects of ocean temperature on survival rates of 120 stocks of Pacific salmon (Oncorhynchus spp.) in northern and southern areas. Can J Fish Aquat Sci 59, 456-463.

Naiman, R.J., Bilby R.E., Schindler D.E., Helfield J.M. (2002) Pacific salmon, nutrients and the dynamics of freshwater and riparian ecosystems. Ecosystems 5, 399-417.

Noakes, D.J., Fang L., Hipel K.W., Kilgour D.M. (2005) The Pacific Salmon Treaty: a century of debate and an uncertain future. Group Decision Negotiation 14, 501-522.

Northcote, T. G., Atagi D.Y. (1997) Pacific salmon abundance trends in the Fraser River watershed compared with other British Columbia systems. Pages 199-219 in D.J. Stouder, P.A. Bisson, R.J. Naiman, editors. Pacific salmon and their ecosystems: status and future option. Chapman and Hall, New York.

Pikitch, E.K., Santora C., Babcock E.A. et al. (2000) Ecosystem-based fishery management. Science 305, 346-347.

Polis G.A., Anderson W.B., Holt R.D. (1997) Toward an integration of landscape and food web ecology: the dynamics of spatially subsidized food webs. Ann Rev Ecol Syst 28, 289-316.

Price, M.H.H., Darimont C.T., Temple N.F., MacDuffee S.M. (2008) Ghost runs: management and status assessment of Pacific salmon (Oncorhynchus spp.) returning to British
Columbia's central and north coasts. Can J Fish Aquat Sci 65, 2712-2718.

Quinn, T.P. (2005) The behaviour and ecology of Pacific salmon and trout. University of Washington Press, Seattle.

Quinn, T.P., Carlson S.M., Gende S.M., Rich Jr. H.B. (2009) Transportation of Pacific salmon carcasses from streams to riparian forests by bears. Can J Zool 87, 195-203.

Quinn, T.P., Hodgson S., Flynn L., Hilborn R., Rogers D.E. (2007) Directional selection by fisheries and the timing of sockeye salmon (Oncorhynchus nerka) migrations. Ecol Appl 17, 731-739.

Reimchen, T.E. (1994) Further studies of black bear and chum salmon in stream and estuary habitats at Bag Harbour, Gwaii Haanas. Page 58. Canadian Parks Service, Queen Charlotte City.

Reimchen, T.E. (1995) Estuaries, energy flow and biomass extraction in Gwaii Haanas. Sea Wind 9, 26-28.

Reimchen, T.E. (2000) Some ecological and evolutionary aspects of bear-salmon interactions in coastal British Columbia. Can J Zool 78, 448-457.

Reimchen, T.E., Mathewson D., Hocking M.D., Moran J., Harris D. (2003) Isotopic evidence for enrichment of salmon-derived nutrients in vegetation, soil and insects in riparian zones in coastal British Columbia. Am Fish Soc Symp 34, 59-69.

Ricker, W.E. (1954) Stock and recruitment. J Fisheries Res Board 11, 559-623.

Roberts, C.M., Bohnsack J.A., Gell F., Hawkins J.P., Goodridge R. (2001) Effects of Marine Reserves on Adjacent Fisheries. Science 294, 1920-1923.

Scheuerell, M.D., Moore J.W., Schindler D.E., Harvey C.J. (2007) Varying effects of anadromous sockeye salmon on the trophic ecology of two species of resident salmonids in southwest Alaska. Freshwater Biol 52, 1944-1956.

Schindler, D.E., Scheuerell M.D., Moore J.W., Gende S.M., Francis R.B., Palen W.J. (2003) Pacific salmon and the ecology of coastal ecosystems. Front Ecol Environ 1, 31-37.

Schindler, D.E., Hilborn R., Chasco B. et al. (2010) Population diversity and the portfolio effect in an exploited species. Nature 465, 609-613.

Schindler, D.E., Leavitt P.R., Brock C.S., Johnson S.P., Quay P.D. (2005) Marine-derived nutrients, commercial fisheries, and production of salmon and lake algae in Alaska. Ecology 86, 3225-3231.

Selbie, D.T., Finney B.P., Barto D. et al. (2009) Ecological, landscape, and climatic regulation of sediment geochemistry in North American sockeye salmon nursery lakes: insight for paleoecological salmon investigations. Limn Oceanogr 54, 1733-1745.

Slaney, T.L., Hyatt K.D., Northcote T.G., Fielden R.J. (1996) Status of anadromous salmon and trout in British Columbia and Yukon. Fisheries 2, 20-35. 
Stoms, D.M., Davis F.W., Andelman S.J. et al. (2005) Integrated coastal reserve planning: making the land-sea connection. Front Ecol Environ 3, 429-436.

Taylor, G.G., Dickie J.L. (2009) Recreating sustainable sockeye fisheries in the Skeena watershed. Fish First Consulting, Salt Spring Island.

Tallis, H., Ferdaña Z., Gray E. (2008) Linking terrestrial and marine conservation planning and threats analysis. Conserv Biol 22, 120-130.

Thirgood, S., Mosser A., Tham S. et al. (2004) Can parks protect migratory ungulates? The case of the Serengeti wildebeest. Anim Conserv 7, 113-120.

Walters, C., LeBlond P., Riddell B. (2004) Does over-escapement cause salmon stock collapse? Technical Paper. Pacific Fisheries Resource Conservation Council, Vancouver.
West, C.D., Dytham C., Righton D., Pitchford J.W. (2009) Preventing overexploitation of migratory fish stocks: the efficacy of marine protected areas in a stochastic environment. ICES J Mar Sci 66, 1919-1930.

Wilkinson, C.E., Hocking M.D., Reimchen T.E. (2005) Uptake of salmon-derived nitrogen by mosses and liverworts in Coastal British Columbia. Oikos 108, 85-98.

Willson, M.F., Halupka K.C. (1995) Anadromous fish as keystone species in vertebrate communities. Conserv Biol $\mathbf{9}$, 489-497.

Zhang, Y.X., Negishi J.N., Richardson J.S., Kolodziejczyk R. (2003) Impacts of marine-derived nutrients on stream ecosystem functioning. Proc Roy Soc Lond 270,

2117-2123. 